\title{
Double-balloon endoscopic ultrasound-guided gastroenterostomy: simplifying a complex technique towards widespread use
}

Endoscopic ultrasound-guided gastroenterostomy (EUS-GE) is a novel technique for the management of gastric outlet obstruction (GOO), which has been shown to be safe and effective [1,2]. To mitigate technical difficulties, a specialized double-balloon catheter was developed in Japan and has been found to be effective when used with an electrocautery-enhanced lumen-apposing metal stent (LAMS) [3]. Outside of Japan, however, this device is unavailable; therefore, in North America and Europe only highly specialized centers are currently performing EUS-GE using techniques that are challenging and with the potential for severe adverse events. Here we describe the performance of double-balIoon EUS-GE using a widely available vascular balloon catheter ( $\vee$ Video 1$)$.

A 72-year-old man with unresectable pancreatic cancer presented with recurrent GOO following previous enteral stenting and was found to have stent tumor ingrowth ( $\triangleright$ Fig.1). A multidisciplinary decision was made to attempt EUS-GE facilitated by double-balloon occlusion. A guidewire was endoscopically advanced through the obstructed stent deep into the jejunum. The endoscope was exchanged through an overtube to prevent looping in the stomach. Two vascular balloon catheters with a compliant balloon diameter reaching up to $46 \mathrm{~mm}$ when inflated (Coda balloon; Cook Medical, Bloomington, Indiana, USA) were fashioned together with the balloons set $10 \mathrm{~cm}$ apart ( Fig.2). The device was advanced distal to the obstruction over the wire using fluoroscopic guidance. The balloons were then inflated to anchor the small bowel and saline with contrast was injected through the proximal catheter, filling the bowel lumen between the balloons. On EUS, the bowel segment was visibly dilated and anchored, thereby facilitating stent insertion (-Fig.3). An electrocautery-en-

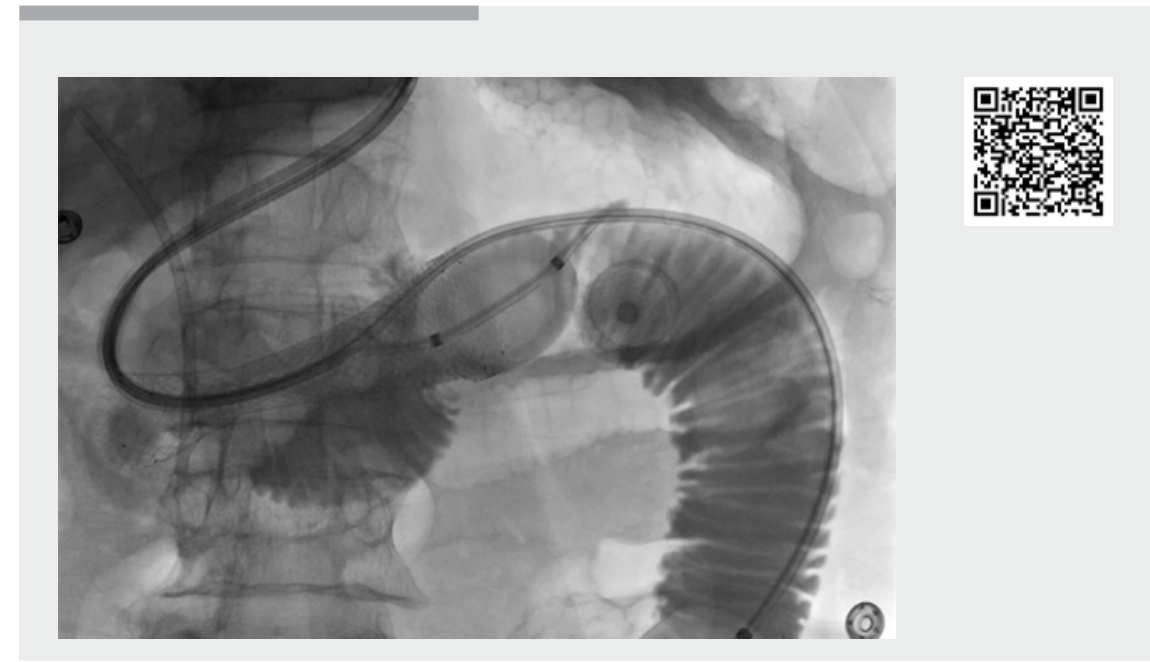

$\checkmark$ Video 1 Endoscopic ultrasound-guided gastroenterostomy for malignant gastric outlet obstruction facilitated by a double-balloon occlusion device made from a widely available vascular balloon catheter.

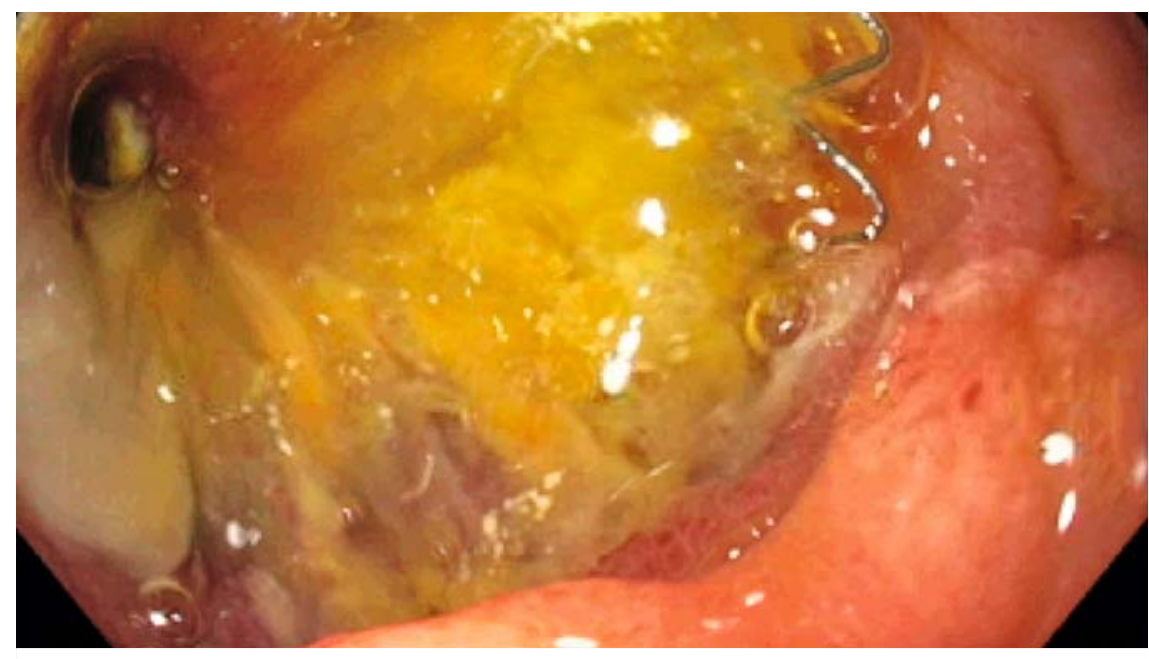

- Fig. 1 Endoscopic view showing enteral stent obstruction caused by pancreatic cancer tumor ingrowth.

hanced 15-mm LAMS was then inserted to complete the gastroenterostomy ( Fig.4).

The patient tolerated a stent diet within 24 hours but required endoscopic revision 6 weeks later owing to blockage of the stent by a potassium chloride pill. No further intervention was subsequently required.

The use of EUS-GE as a first-line treatment of $\mathrm{GOO}$ is limited by technical challenges. The presently described double-balloon EUS-GE greatly facilitated the procedure using a device that is widely 


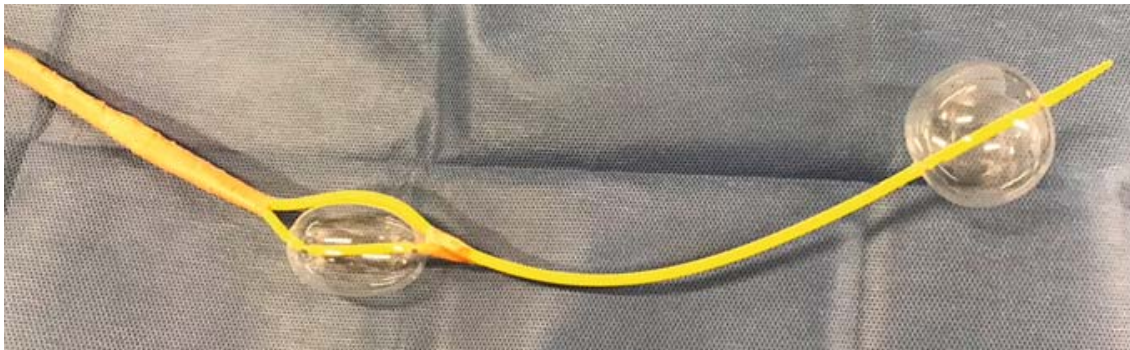

Fig. 2 A double-balloon occlusion device made by connecting two radiologic vascular balloon catheters with the balloons set $10 \mathrm{~cm}$ apart.

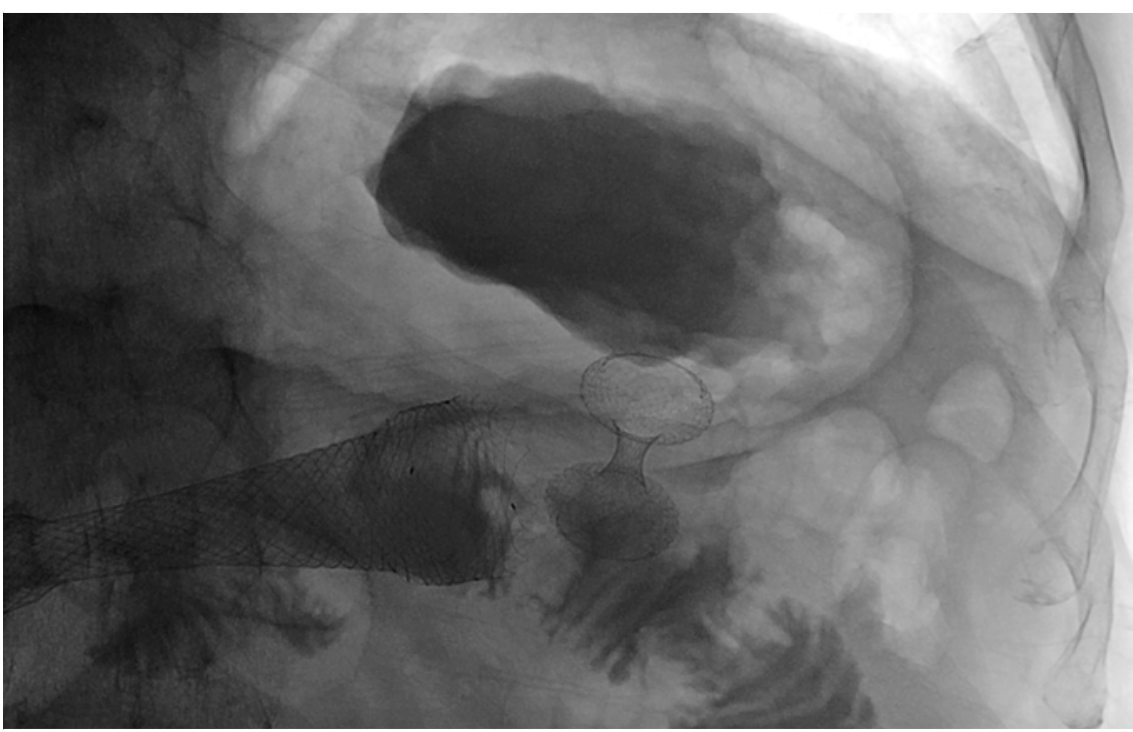

Fig. 4 Fluoroscopic image of the lumen-apposing metal stent anastomosing the stomach to the small bowel distal to the enteral stent.

available. This may be a first step towards dissemination of this modality and will likely encourage high quality prospective trials to evaluate its role.

\section{Endoscopy_UCTN_Code_TTT_1AS_2AG}

\section{Competing interests}

Yen-I Chen is a consultant for Boston Scientific. All other authors have disclosed no potential competing interests to disclose.
The authors

Corey S. Miller ${ }^{1}$, Yen-I Chen ${ }^{1}$, Yamile Haito Chavez $^{2}$, Adel Alghamdi ${ }^{1}$, George Zogopoulos $^{3}$, Ali Bessissow ${ }^{4}$

1 Division of Gastroenterology and Hepatology, McGill University Health Centre, Montreal, Quebec, Canada

2 Gastro Avanza Centro de Endoscopia Avanzada, Clinica Arequipa, Arequipa, Peru

3 Department of Surgery, McGill University Health Centre, Montreal, Quebec, Canada

4 Department of Radiology, McGill University Health Centre, Montreal, Quebec, Canada

Corresponding author

\section{Yen-I Chen, MD}

McGill University Health Centre, 1001

Decarie Blvd, Montreal, QC, H4A 3]1, Canada yen-i.chen@mcgill.ca

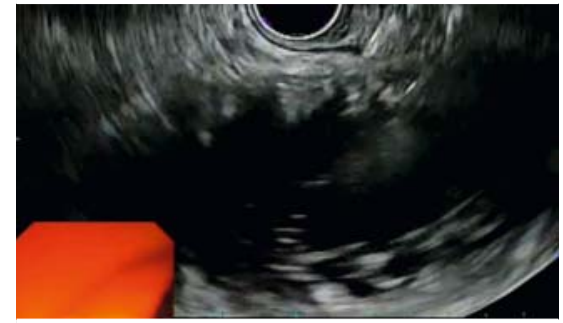

- Fig. 3 Endoscopic ultrasound image of the dilated fluid-filled small-bowel segment between the two occluding balloons.

\section{References}

[1] Chen YI, Itoi T, Baron TH et al. EUS-guided gastroenterostomy is comparable to enteral stenting with fewer re-interventions in malignant gastric outlet obstruction. Surg Endosc 2017; 31: $2946-2952$

[2] Chen YI, James TW, Agarwal A et al. EUSguided gastroenterostomy in management of benign gastric outlet obstruction. Endosc Int Open 2018; 6: E363-E369

[3] Itoi T, Ishii K, Ikeuchi $\mathrm{N}$ et al. Prospective evaluation of endoscopic ultrasonographyguided double-balloon-occluded gastrojejunostomy bypass (EPASS) for malignant gastric outlet obstruction. Gut 2016; 65: $193-195$

\section{Bibliography}

DOI https://doi.org/10.1055/a-0991-7530

Published online: 17.9.2019

Endoscopy 2019; 51: 151-152

(c) Georg Thieme Verlag KG

Stuttgart · New York

ISSN 0013-726X

\section{ENDOSCOPY E-VIDEOS}

https://eref.thieme.de/e-videos

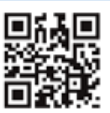

Endoscopy E-Videos is a free access online section, reporting on interesting cases and new

techniques in gastroenterological endoscopy. All papers include a high quality video and all contributions are freely accessible online.

This section has its own submission website at https://mc.manuscriptcentral.com/e-videos 